\title{
Increased Platelet Monoamine Oxidase Activity in Patients on Acute Stage of Ischemic Insult as A Potential Biomarker of a Better Functional Outcome of the Illness
}

\author{
Uzbekov $M^{* 1}$, Alferova $V^{2}$, Shikhov $S^{1}$, Mayorova $L^{3}$, Kuptsova $S^{3}$, Petrushevsky $A^{2}$ and Strelkova $I^{2}$ \\ ${ }^{1}$ Moscow Research Institute of Psychiatry, Russia \\ ${ }^{2}$ Center of speech pathology and neurorehabilitation, Russia \\ ${ }^{3}$ Center of speech pathology and neurorehabilitation of the Institute of Higher Nervous Activity and Neurophysiology RAS, Russia \\ *Corresponding author: Uzbekov M, Head of the Laboratory of Brain Pathology, Moscow Research Institute of Psychiatry, \\ Moscow, Russia
}

\section{ARTICLE INFO}

Received: 幽 April 30, 2019

Published: May 06, 2019

\begin{abstract}
Citation: Uzbekov M, Alferova V, Shikhov S, Mayorova L, Kuptsova S, Petrushevsky A, Strelkova I. Increased Platelet Monoamine Oxidase Activity in Patients on Acute Stage of Ischemic Insult as A Potential Biomarker of a Better Functional Outcome of the Illness. Biomed J Sci \& Tech Res 17(4)-2019. BJSTR. MS.ID.003047.
\end{abstract}

\section{Introduction}

Alteration of biogenic monoamines (serotonin and dopamine) metabolism is one of the pathogenetic mechanisms that affect processes of neuroplasticity during focal brain ischemia [1]. It is known that recovery and compensation of disturbed functions after focal brain pathology (in particular, ischemic insult) are related to different mechanisms of neuroplasticity, that become activated at different structural levels of the central nervous system (CNS) (molecular, synaptic, and cellular). Platelet monoamine oxidase (MAO) activity that may reflect MAO activity in the brain may be used in clinical studies as an integral index of changes in monoamine metabolism [2]. Biological markers are the indicators of pathological condition because they are connected with pathophysiological processes. They can give information and permit to investigate very fine molecular mechanisms of the disease.

In spite that that aetiology of neurological diseases is still unknown the biomarker or the combination of biomarkers characterizing clinical syndrome or syndromes can help to improve diagnosis, prediction process and evaluation of the efficacy of the intervention and contribute to the development of the new thera peutical approaches and elucidation of pathogenetic mechanisms of the pathologies. The aim of the investigation was to study platelet MAO activity in patients in the acute period of ischemic insult (on the $3^{\text {rd }}-5^{\text {th }}$ day after insult) and to determine the clinical-biochemical correlations of MAO activity with the functional outcome on the $21^{\text {st }}$ day after the insult.

\section{Materials and Methods}

There were examined 25 patients (the average age was $67 \pm 10$ years, 14 women and 11 men) with the first hemispheric insult in the acute period of the insult (1-21 days). In all cases, the diagnosis of ischemic insult in the carotid system was verified by neuroimaging methods (computer or magnetic resonance tomography of the brain). The severity of the neurological deficit in patients on arrival (the $1^{\text {st }}$ to $2^{\text {nd }}$ day of the illness) and on discharge from the hospital ( $21^{\text {st }}$ day) was measured using the NIHSS clinical scale [3]. The degree of functional recovery of patients upon discharge from the hospital (21't day) was evaluated using the Bartel Index scale [4]. All patients received a standard basic and differentiated therapy for ischemic insult.Criteria for the exclusion of patients from the study 
included hemorrhagic insult, a severe state of patients associated with a decreased level of wakefulness, and psychic illnesses or previous focal CNS injuries.

The control group consists of 17 subjects with demographic characteristics similar to the characteristics of patients with ischemic insult (Student's t test, $\mathrm{P}<0.1$ ) with no clinical signs of chronic cerebrovascular insufficiency. All patients and subjects from the control group gave informed consent for participation in the clinical study. The study was performed in accordance with the Helsinki Declaration on experiments involving human beings. The activity of monoamine oxidase of platelets was measured using the method [5] in all patients on the 3rd-5th day of the illness. Statistical analysis of the data was performed using STATISTICA software, version 6. Differences were considered as significant at $\mathrm{P}<0.05$.

\section{Results and Discussion}

A moderate or good recovery of neurological functions during the acute period of the insult (1-21 days) was observed in $72 \%$ of the patients (a Bartel Index of 70-80 points; a NIHSS of 6-8 points). In other cases ( $18 \%$ of the patients), the recovery of neurological functions was minimal. These patients had a strong and predominantly motor neurological deficit and speech disturbances of different severities (a Bartel Index of 50-65 points; a NIHSS of12-14 points). No lethal outcomes occurred in the group of patients In $64 \%$ of the patients, we found a considerable increase in platelet MAO activity on the $3^{\text {rd }}-5^{\text {th }}$ day of the illness, as compared to control group (Mann-Whitney $\mathrm{U}$ test, $\mathrm{P}<0.00001$ ). In the group of patients with ischemic insult, MAO activity was $16.10 \pm 8.5$ nmole benzaldehyde/mg protein/hour, that was significantly higher, almost 2.6 times, as compared with the control group $(8.70 \pm 0.7$ nmole benzaldehyde/mg protein/hour).

The results reflect the strong activation of deamination process in patients with ischemic insult. May be that is connected with the increased level of monoamines (catecholamines and serotonin) in the acute period of the illness. The increase in platelet MAO activity that may reflect the MAO activity in the brain [2], may result in a decrease in the level of catecholamines and serotonin. This can be considered as a compensatory response that stabilizes homeostasis during the acute period of ischemic insult. This compensatory mechanism is associated with a better functional outcome of the illness, which was confirmed by significant correlations between the MAO activity and neurological deficit in patients with ischemic insult. Significant correlations (with opposite signs) were observed between the MAO activity on the 3rd-5th day of the illness and neurological deficit score (NIHSS) and the functional recovery of patients (the Bartel Index) on the 21st day of the illness (MAO/NIHSS: $r=-0.72, \mathrm{P}=0.04 ; \mathrm{MAO} /$ Bartel Index: $\mathrm{r}=+0.66, \mathrm{P}<0.05$ ).

A decrease in the neurological deficit accompanied by a decrease in the NIHSS score and an increase in the Bartel Index was associated with an increase in the activity of platelet MAO. The results of regression analysis also suggested that there is a significant negative correlation between the MAO activity on the $3^{\text {rd }}-5^{\text {th }}$ day of the illness and the recovery of neurological functions on the 21st day after ischemic insult (summary NIHSS score; contingency test $\left(\chi^{2}-1\right)=7.47, P=0.005$ (odds ratio OR = 1.29). The increase in MAO activity during the acute period of ischemic insult was associated with one of the compensatory responses that stabilize the homeostasis of the patient's body and provide conditions for better recovery of neurological functions. There is an important poorly investigated problem of the recovery of disturbed neurological functions on the late stages after ischemic insult. Our preliminary experimental results in which poststroke patients underwent brain scanning with analysis of functional (resting state fMRI) and anatomical connectivity at different (chronic) stages of disease allowed us to identify some patterns of the recovery process. It was found that the recovery of speech was reflected in the strengthening of large-scale interhemispheric functional connectivity and of the left intrinsic connectivity of the frontotemporoparietal region (according to the resting state fMRI. Thus, the increased platelet MAO activity in the acute period of insult may be considered as a positive potential serological biomarker of the functional outcome of the illness on the $21^{\text {st }}$ day of ischemic insult.

\section{References}

1. Holschneider DP, Scremin OU, Huynh L, Chen K, Shih JC (1999) Lack of protection from ischemic injury of monoamine oxidase B-deficient mice following middle cerebral artery occlusion. Neuroscience Letters 259(3): 161-164

2. Chen K, Wu HF, Shih JC (1993) The deduced amino acid sequences of human platelet and frontal cortex monoamine oxidase are identical. J Neurochem 61(1): 187-190.

3. Frankel MR, Morgenstern LB, Kwiatkowski T, Lu M, Tilley BC, et al. (2000) Predicting prognosis after stroke: a placebo group analysis from the National Institute of Neurological Disorders and Stroke rt-PA Stroke Trial. Neurology 55(7): 952-959.

4. Mahoney F, Barthel D (1965) Functional evaluation: the Barthel index. MD State Med J 14: 61-65.

5. Voloshina ON, Moskvitina TA (1985) Method of estimation of platelet monoamine oxidase activity. Lab Delo 5: 289-291. 
ISSN: 2574-1241

DOI: 10.26717/BJSTR.2019.17.003047

Uzbekov M. Biomed J Sci \& Tech Res

(C) $(9)$ This work is licensed under Creative

Submission Link: https://biomedres.us/submit-manuscript.php

$\begin{array}{ll}\text { BIOMEDICAL } & \text { Assets of Publishing with us } \\ \text { RESEARCHES } & \text { Global archiving of articles } \\ & \text { - Immediate, unrestricted online access } \\ \end{array}$

